\title{
0 Ensino Religioso e a diversidade religiosa no Brasil: desafios para a educação
}

\author{
Religious Education and religious diversity in \\ Brazil: challenges for education
}

\begin{abstract}
Gisela Waechter Streck
Doutora em Teologia pela Escola Superior de Teologia, professora adjunta do Programa de Pós-Graduação em Teologia e coordena o mestrado profissional em Teologia da Escola Superior de Teologia, São Leopoldo, RS - Brasil, e-mail: gisela.streck@uol.com.br
\end{abstract}

\section{Resumo}

O presente artigo trata do Ensino Religioso como disciplina escolar. Faz um breve resgate histórico a partir das constituições brasileiras, enfatizando as discussões e as polêmicas em torno de sua inclusão ou não na escola. No texto, são apresentados dados sobre a diversidade em termos de religiosidade no Brasil e aspectos relevantes a serem considerados numa educação que leve em conta a pluralidade religiosa do país. Reflete sobre as possibilidades de educar o ser humano para a alteridade e para a tolerância. Conclui que o Ensino Religioso na escola pode ser um dos espaços para educar para a tolerância, por meio de um diálogo em que haja respeito e sensibilidade para conviver com as diferentes tradições religiosas presentes em sala de aula.

Palavras-chave: Ensino Religioso. Diversidade. Educação para a tolerância. Diálogo. 


\section{Abstract}

This article deals with Religious Education as a school subject. It includes a brief historical overview based on the Brazilian constitutions, emphasizing the discussions and polemics concerning the inclusion of Religious Education or not in the schools. The text presents data about diversity regarding religiosity in Brazil and relevant aspects to be considered in a kind of education that takes into account the religious plurality in the country. It reflects on the possibility of educating human beings for alterity and for tolerance. It concludes that religious education in the school may be one of the spaces for tolerance through a dialogue in which there is respect and sensibility to accept the presence of different religious traditions within the classroom.

Keywords: Religious education. Diversity. Education for tolerance. Dialogue.

\section{Introdução}

O Ensino Religioso é uma disciplina presente na escola brasileira desde sempre, mas, até hoje, sua inclusão gera polêmica e sua exigência como disciplina escolar é contestada. A disciplina recebeu tratamento específico em todas as constituições brasileiras, menos na de 1891, que declarava no Art. 72 parágrafo sexto: "Será leigo o ensino ministrado nos estabelecimentos públicos". Nas demais, e até na de 1988, ora em vigor, o Ensino Religioso nas escolas não só foi contemplado nos itens da Educação, como desencadeou polêmicas e discussões que envolveram a sociedade, a Igreja Católica e diferentes grupos. As discussões, das quais o Ensino Religioso foi protagonista, estavam vinculadas ao debate acerca da questão sobre o direito de quem poderia ensinar e o que se poderia ensinar na escola.

A realidade brasileira é plurirreligiosa e traz como característica a diversidade. O Ensino Religioso está inserido neste contexto e é afetado diretamente por ele. Por um lado, a disciplina tem lei específica que a regulamenta. Por outro lado, precisa dar conta da diversidade em termos de diferentes tradições religiosas presentes tanto na sociedade brasileira como na escola. 
A questão a ser refletida é como a escola (e o Ensino Religioso) pode educar o ser humano de hoje e a sua busca por dar sentido para sua vida, levando em conta uma realidade brasileira que é plurirreligiosa e que tem como característica fundamental a diversidade religiosa.

\section{O Ensino Religioso e seu desenvolvimento no contexto educacional brasileiro}

A Constituição de 1934 no Art. 153 afirmava: "O ensino religioso será de frequência facultativa, e ministrado de acordo com os princípios da confissão religiosa do aluno manifestada pelos pais ou responsáveis e constituirá matéria dos horários nas escolas públicas primárias, secundárias, profissionalizantes e normais”. A Constituição de 1937 no Art. 133 afirmava: "O ensino religioso poderá ser contemplado como matéria do curso ordinário das escolas primárias, normais e secundárias. Não poderá, porém, constituir objeto de obrigação dos mestres ou professores, nem de frequência compulsória por parte dos alunos".

As Constituições de 1934 e 1937 refletem, na questão do Ensino Religioso, a polêmica entre dois grupos que defendiam posições ideológicas divergentes a respeito da educação: o movimento renovador e a ala católica. O primeiro estava preocupado com a nova situação político-social que se mostrava no país e a necessidade de corresponder à demanda desta nova realidade. Se antes, na "ordem social oligárquico-aristocrática" a educação era privilégio das elites e estas podiam pagar por ela, agora a realidade era outra. Romanelli (1991) afirma: "Outra era, porém, a situação que começava a configurar-se na ordem burguesa. As classes médias em ascensão reivindicavam o ensino médio, e as camadas populares, o ensino primário". Para o movimento renovador este era o momento de o Estado "assumir o controle da educação" e proporcionar uma escola gratuita, obrigatória e acessível para todos. Esta escola só poderia ser leiga: "Como ensino ministrado pelo Estado, numa sociedade heterogênea, ele só poderia ser leigo, a fim de garantir aos educandos o respeito à sua personalidade e confissão religiosa e a fim de evitar que a escola se transformasse em instrumento de propaganda de doutrinação religiosa”. Já a ala 
católica entendeu que uma escola pública, leiga e gratuita era sinônimo de monopólio estatal e não percebeu que, na verdade, "nem o Estado tinha condições materiais de implantar o monopólio, nem tinha a intenção de fazê-lo" (ROMANELLI, 1991).

A Igreja Católica, que tinha o monopólio do ensino médio defendia o ensino religioso nas escolas públicas. Em Texto da Conferência Nacional dos Bispos do Brasil (1996) se afirma que a partir do "princípio de que a educação era prolongamento do direito familiar, o ensino religioso deveria ser dado, pois, de conformidade com a família do aluno" ${ }^{1}$. Assim, o Ensino Religioso confessional começa a fazer parte integrante da escola pública, como conquista da Igreja Católica e/ou concessão do Governo: "Fazendo-o incluir nas duas constituições, quis o Governo adotar nesse primeiro período [...], uma política de conciliação e compromisso" (ROMANELLI, 1991).

Em 1946, é promulgada uma nova Constituição e o Art. 168, item V afirma: "o Ensino Religioso constitui disciplina dos horários das escolas oficiais, é de matrícula facultativa e será ministrado de acordo com a confissão religiosa do aluno, manifestada por ele, se for capaz, ou pelo seu representante legal ou responsável". Até 1961 a educação brasileira foi regida por leis, chamadas de Leis Orgânicas. Nos seis decretos que abordam o ensino religioso, este é tratado ou como "prática educativa" ou como "parte dos estudos" ou ainda como "disciplina". Durante este período e até 1961, quando foi promulgada a Lei de Diretrizes e Bases, Lei n. 4.024, que regulamentou o texto constitucional, retornou ao cenário brasileiro a polêmica acerca da escola pública e particular. Novamente dois grupos principais discutiram a questão. De um lado, a Igreja Católica, ou como ela mesma se denomina "os partidários da democracia", partia do princípio de que "os direitos naturais da pessoa humana devem ser respeitados pelo Estado". Defendia-se a tese: "Cabe prioritariamente à Igreja e à Família e, subsidiariamente, ao Estado o direito de promover a educação". Já o outro grupo, chamado pelos católicos de "partidários da filosofia do fascismo e congêneres", o qual defendia o princípio que "o indivíduo só tem os direitos que o Estado lhe concede", argumentavam: "[...] é erro continuar a

\footnotetext{
1 Para mais informações sobre a atuação da Igreja Católica nessa questão, cf. também p. 49-54.
} 
escola na mão de particulares, pois além de ter fins econômicos, é privilégio dos ricos, é separatista das classes sociais e empecilho para o progresso cultural do povo" (CNBB, 1996, p. 67).

A polêmica em torno da escola pública e particular terminou com a promulgação da Lei de Diretrizes e Bases (LDB) em 1961, que regulamentou a questão. Mais uma vez, a Igreja Católica, a partir do seu empenho, conseguiu manter o Ensino Religioso confessional na escola pública. A Lei n. 4.024, art. 90 (BRASIL, 1961) afirmava:

o Ensino Religioso constitui disciplina dos horários normais das Escolas Oficiais, é de matrícula facultativa e será ministrado sem ônus para os poderes públicos, de acordo com a confissão religiosa do aluno, manifestada por ele, se for capaz, ou pelo seu representante legal ou responsável.

Parágrafo $1^{\circ}$ : A formação de classe para o Ensino Religioso independe de número mínimo de alunos.

Parágrafo 2: O registro dos professores de Ensino Religioso será realizado perante a autoridade religiosa respectiva.

Apesar da aparente vitória, a Igreja Católica reconheceu que a postura do Estado era muito mais de omissão ao não assumir os encargos financeiros e considerar o professor de ensino religioso "um agente educacional ocasional, alienado do sistema escolar".

A partir da década de 1970 processa-se uma mudança no tratamento da questão do Ensino Religioso nas escolas. Como igreja hegemônica no Brasil, a Igreja Católica, até a década de 1960, não só se empenhou pela manutenção da disciplina como determinou seu modo de ser. Nas escolas públicas, foram desenvolvidas a catequese escolar, acentuando a confessionalidade e a doutrinação. A partir da Lei n. 5.692 de 1971 (BRASIL, 1971), os Estados da Federação começam a organizar suas próprias leis e inicia-se um período de intensa atividade. A Igreja Católica, por meio da Conferência Nacional dos Bispos do Brasil (CNBB), acompanhou as experiências que os Estados realizaram e lançou seu "Plano Bienal" de 19731974 e 1975-1976 (CNBB, 1996, p. 65-6, 72-3).

Em Santa Catarina, a partir de 1970, a disciplina recebe a designação de Educação Religiosa Escolar (ERE) e tem um caráter ecumênico. Por iniciativa da Igreja Católica, diferentes igrejas cristãs reuniram-se pela 
primeira vez em uma Assembleia de Confissões Religiosas para Educação Religiosa em Florianópolis, e criaram o Conselho Interconfessional para Educação Religiosa (CARON, 1996, p. 8).

No Paraná, foi criada a Associação Interconfessional de Educação de Curitiba (Assintec) em 1973, com o objetivo de propor para as escolas um "ensino religioso interconfessional", e em 1985, o projeto foi implantado em todo o Estado (BOSCARDIN, 1996, p. 9). Do mesmo modo, no Rio Grande do Sul, a Igreja Católica se reuniu com diferentes igrejas cristãs para, juntas, elaborarem um ensino religioso interconfessional para as escolas públicas, a partir de 1972 (GTERI, 1996, p. 6-7).

Com o fim do regime militar em 1984 e o início do período chamado de "Nova República", o país busca uma redemocratização e começam os estudos e debates para a elaboração de uma nova Constituição. Na educação, o país busca uma redemocratização do ensino e a sociedade brasileira é chamada a participar. A nova Constituição é promulgada em 1988 e no seu Art. 210, parágrafo primeiro afirma-se: "O Ensino Religioso, de matrícula facultativa, constituirá disciplina dos horários normais das escolas públicas de ensino fundamental".

O Ensino Religioso mais uma vez se mantém na Constituição e suscita amplo debate entre aqueles que são a favor e contra sua manutenção no ensino público. Henry Sobel (1996, p. 6), presidente do Rabinato da Congregação Israelita Paulista, se diz radicalmente contra o ensino religioso na escola pública e argumenta que a escola é um "ambiente inapropriado para a instrução religiosa". Um dos problemas está relacionado à atuação dos professores: "Para que o ensino religioso pudesse cumprir seus objetivos, seria necessário que os professores fossem dotados de altíssimo grau de sensibilidade, discernimento e equilíbrio, a fim de não imporem, até mesmo subliminarmente, sua própria linha religiosa". Sobel afirma que o artigo 210 da Constituição, ao declarar o ensino religioso facultativo, estigmatiza aquelas crianças cujos pais optaram por uma educação ateísta ou agnóstica. Therezinha M. L. da Cruz (1996, p. 6), membro da diretoria do Conselho Nacional de Igrejas Cristãs, coloca a questão a partir de uma outra perspectiva: "[...] pensar no Ensino Religioso a partir das escolas". E traz uma pergunta que considera fundamental: "[...] que contribuição o Ensino Religioso pode dar à qualidade da educação?" 
Iyá S. Medeiros (1996, p. 7), porta-voz da Comissão Afro-Brasileira para Assuntos de Ensino Religioso, faz uma clara separação entre deveres da família, da escola e da Igreja: "À escola cabe ensinar, à família cabe educar, e ao Templo, Igreja, Sinagoga, Terreiro, Centro Espírita, guiar as crianças e os jovens pelos mares da religião escolhida". O grupo que representa se posiciona contra o ensino religioso na escola e sugere uma disciplina chamada "Filosofia da Religião" na qual todas as religiões existentes possam ser contempladas, mas "sem se aprofundar em dogmas religiosos, com visão múltipla e plurirreligiosa”.

Em 1996, está concluída a nova Lei de Diretrizes e Bases da Educação, Lei n. 9.394 de 1996 (BRASIL, 1996), e afirma:

o Ensino Religioso, de matrícula facultativa, constitui disciplina dos horários normais das escolas públicas de ensino fundamental, sendo oferecido, sem ônus para os cofres públicos, de acordo com as preferências manifestadas pelos alunos ou por seus responsáveis, em caráter:

I - confessional, de acordo com a opção religiosa do aluno ou de seu responsável, ministrado por professores ou orientadores religiosos preparados e credenciados pelas respectivas igrejas ou entidade religiosa;

II - interconfessional, resultado de acordo entre as diversas entidades religiosas, que se responsabilizarão pela elaboração do respectivo programa.

O texto da lei não trouxe novidades e não agradou aos grupos que, no período que antecedeu à elaboração da Constituição, lutaram pela permanência da disciplina na escola pública. Além de permanecer a confessionalidade, mesmo respeitando as diferentes confissões religiosas, a questão que mais causou polêmica e desagrado foi o fato de que "cabe à escola oferecê-lo, porém, sem que represente qualquer ônus para o Estado, restando às organizações religiosas a definição de conteúdos e a garantia dos professores". A partir da insatisfação de comunidades escolares e das Igrejas, logo após a promulgação da Lei, inicia-se uma mobilização para mudança da LDB no Congresso Nacional. Ao todo, são três Projetos de Lei que propõem modificações e têm em comum o princípio de que "o ensino religioso é parte integrante essencial da formação do ser humano, como pessoa e cidadão". Assim, também o Estado deve "promovê-lo, não só pela previsão 
de espaço e tempo na grade horária curricular do ensino fundamental público, mas também pelo seu custeio, quando não se revestir de caráter doutrinário ou proselitista" (PADRE ROQUE, 1998, p. 6). O texto substitutivo, apresentado pelo Deputado Federal Padre Roque, foi aprovado na Câmara dos Deputados e no Senado da República e sancionado pelo Presidente da República em 22 de julho de 1997.

Pela Lei n. 9.475, o Art. 33 da Lei n. 9.394/96 ganha nova redação.

Art. 33: o ensino religioso, de matrícula facultativa, é parte integrante da formação básica do cidadão e constitui disciplina dos horários normais das escolas públicas de ensino fundamental, assegurado o respeito à diversidade cultural religiosa do Brasil, vedadas quaisquer formas de proselitismo. Parágrafo primeiro: Os sistemas de ensino regulamentarão os procedimentos para a definição dos conteúdos do ensino religioso e estabelecerão as normas para a habilitação dos professores;

Parágrafo segundo: Os sistemas de ensino ouvirão entidade civil, constituída pelas diferentes denominações religiosas, para a definição dos conteúdos do ensino religioso.

Até a promulgação da Lei n. 9.475 (BRASIL, 1997), o ensino religioso na escola teve um traço comum: ele sempre foi confessional, apesar de assegurar "aos pais ou responsáveis a opção pela confissão religiosa na qual o ensino religioso escolar de seus filhos seria ministrado". Conforme Padre Roque (1998, p. 3), o objetivo da lei que ora entra em vigor é outro:

enfim, o sentido da lei está em garantir que a escola de ensino fundamental oportunize aos alunos o acesso ao conhecimento religioso. Não é seu interesse fazer com que a escola garanta aos estudantes o acesso às formas institucionalizadas de religião - isto é competência das próprias igrejas e crenças religiosas. À escola compete garantir o acesso ao conhecimento religioso, a seus componentes epistemológicos, sociológicos e históricos.

Nessa nova forma, o ensino religioso não tem a função de educar confessionalmente, mas de "proporcionar, na educação escolar, oportunidade para que o educando descubra o sentido mais profundo da existência; 
encontre caminhos e objetivos adequados para sua realização; e valores que lhe norteiem o sentido pleno da própria vida”.

O Ensino Religioso, como área de conhecimento, tem no fenômeno religioso seu objeto de estudo, definido como "[...] o processo de busca que o ser humano realiza na procura da transcendência, desde a experiência pessoal do Transcendente até a experiência religiosa da partilha de grupo; desde a vivência em comunidade até a institucionalização pelas Tradições Religiosas" (PADRE ROQUE, 1998, p. 9)

O conteúdo próprio da disciplina é o conhecimento religioso, que é "veiculado no Ensino Religioso, enquanto conhecimento humano historicamente constituído, sem a conotação de conhecimento revelado" e como tal, tem seu lugar legitimamente assegurado na escola. No Referencial Curricular para a Proposta Pedagógica da escola, do Fórum Nacional Permanente do Ensino Religioso (Fonaper) se afirma que o conhecimento religioso "visa a subsidiar o educando no entendimento que ele tem a respeito do fenômeno religioso que experimenta e observa no seu contexto" (VIESSER; VIDOTTI; BOSCARDIN, 2000, p. 19).

Os Parâmetros Curriculares Nacionais para o Ensino Religioso (PCNER), do Fonaper (VIESSER; WAGNER; BOHNE, 1997, p. 22), asseguram que o conhecimento religioso é patrimônio humano e estando disponível, a escola "não pode recusar-se a socializá-lo". Por outro lado, deixam claro que não é função da escola "propor aos educandos a adesão e vivência desses conhecimentos, enquanto princípios de conduta religiosa confessional".

\section{A diversidade religiosa brasileira}

O Brasil é um país plurirreligioso, com um grande número de católicos. Pelo Censo realizado em 2000, mesmo apresentando um decréscimo da população católica e um crescimento dos assim chamados "evangélicos", chega-se à conclusão que o país ainda é majoritariamente católico, com 73,9\%. Os evangélicos (protestantes, pentecostais, neopentecostais) somam $15,6 \% ; 7,4 \%$ se declararam sem religião, perfazendo esses três 
grupos $89,5 \%$ da população brasileira. As religiões não cristãs, como a umbanda, o espiritismo, o candomblé somam 2,65\%.

Destes dados numéricos é possível tirar algumas considerações. De acordo com as observações de Follmann (2006, p. 19), entre os evangélicos, são as igrejas pentecostais e neopentecostais as que mais cresceram, em detrimento das igrejas históricas: em 1930, estas representavam $73 \%$ e "no censo de 2000 a relação se inverte e são os pentecostais e neopentecostais que passam a somar $73 \%$ no contexto evangélico no país". Cresceu também o número de pessoas que se declararam sem religião: em 1940 eram $0,2 \%$ e hoje somam $7,4 \%$, ou seja, são 12,4 milhões de pessoas. Também as religiões orientais tiveram um maior crescimento, representado principalmente pelo budismo, que soma 245 mil membros no Brasil.

Por outro lado, é interessante entender o cenário religioso brasileiro para além dos números, que representam a filiação declarada a uma religião, no Censo de 2000. No caso dos sem religião, "esse grupo não congrega pessoas necessariamente ateias, mas também aquelas des-institucionalizadas, afastadas de instituições religiosas”. Neste caso, esse grupo é representativo de uma tendência que mostra o quanto as igrejas ditas tradicionais, ou seja, as religiões mais institucionalizadas perderam sua força de adesão e influência entre os membros. Por outro lado, o número dos sem religião não necessariamente significa uma diminuição da importância que a religiosidade representa para o povo brasileiro: uma pesquisa mostrou que $98 \%$ da população acredita em Deus (SCHULTZ, 2009, p. 23).

Também os baixos índices de filiação ao candomblé, à umbanda e ao espiritismo não significa que estas estão em declínio, mesmo que tenham diminuído em termos percentuais de 4\% em 1991 para 3\% em 2000. Antes, mostra uma realidade tipicamente brasileira: muitos daqueles que frequentam os terreiros de umbanda ou candomblé ou as sessões espíritas se declaram católicos ou protestantes. Uma pesquisa também realizada em 2000 mostra que 25\% dos entrevistados frequentam mais de uma religião. Este dado é uma característica da religiosidade brasileira: muitos se declaram católicos ou protestantes e frequentam também outras religiões, ou no caso dos católicos afirmam serem católicos, mas não praticantes (SCHULTZ, 2006, p. 26). 


\section{O Ensino Religioso e a diversidade: desafios para educar a tolerância}

A partir da Lei que rege o Ensino Religioso no Brasil, três aspectos devem ser destacados:

- é parte integrante da formação básica do cidadão;

- fica assegurado o respeito à diversidade cultural religiosa do Brasil;

- ficam vedadas quaisquer formas de proselitismo.

Conforme o Referencial Curricular do Fonaper (VIESSER; VIDOTTI; BOSCARDIN, 2000, p. 8), o Ensino Religioso na escola não quer fomentar a adesão a um grupo religioso específico, mas oportunizar "os fundamentos do fenômeno religioso no cotidiano da vida, objetivando compreender a busca do Transcendente e o sentido da vida que oferecem critérios e segurança ao exercício responsável dos valores universais da cidadania".

O Ensino Religioso oportuniza o conhecimento religioso e, de acordo com o Referencial Curricular do Ensino Religioso, "não é uma mera informação de conteúdos religiosos, um saber pelo saber". É antes um "saber de si" que oportuniza ao educando conhecer e entender a sua busca pelo Transcendente. Por outro lado, também quer permitir conhecer para valorizar e respeitar "a trajetória particular de cada grupo, proporcionar a convivência fraterna de modo que o educando possa vivenciá-la" (VIESSER; VIDOTTI; BOSCARDIN, 2000, p. 22-23). Neste sentido, é também um "saber dos outros, com os outros". Se por um lado, o Ensino Religioso oportuniza uma busca pessoal pelo Transcendente, por outro lado também abre espaço para uma vivência e uma partilha desta busca, para o diálogo com o outro, sem que isso se deva caracterizar como ensino de uma determinada religião.

Uma pesquisa realizada por Ribeiro (2009, p. 265) entre jovens universitários sobre religiosidade concluiu que estes, na sua busca por dar sentido à vida, "[...] se apoiam menos em crenças e em valores estabelecidos, que não lhes parecem tão sólidos, e mais no próprio empoderamento [...]”. A pesquisa mostrou que os jovens estão agudamente engajados na questão da religiosidade: "O fato de as sociedades modernas terem se apartado da religião e de as esferas da existência terem conquistado autonomia [...] não 
significa que os jovens não estejam engajados na busca por dar sentido para sua vida". Mesmo que os resultados da pesquisa são "um retrato da mutante religiosidade do jovem", de acordo com as palavras do pesquisador, que teve como objetivo "captar flagrantes fotográficos" de um contexto específico, os dados possibilitam pensar estratégias para educar jovens na sua religiosidade, respeitando seu momento de vida e suas opções e escolhas.

O desafio para quem educa é colocar-se a caminho com os jovens, como um companheiro de jornada, que ouve, dialoga, orienta, pois nesta fase da vida, os valores e a própria religiosidade ainda não são definitivos, mas estão em formação. Na busca por sentido de vida e entendimento de si mesmos, necessitam de pessoas que queiram ouvi-los, antes de falar; que estejam dispostas a entendê-los, antes de trazer verdades prontas, e que estejam imbricadas de realidades e do cotidiano de suas vidas.

Ribeiro (2009, p. 244) apresenta etapas ou bases para uma didática da religiosidade. Em primeiro lugar, levar em conta aquilo que jovens trazem consigo em relação aos seus valores, experiências, memórias, rituais, símbolos; num segundo momento, propiciar espaços de partilha e de acolhimento, num movimento que sai de si e abre-se ao outro e à sua religiosidade. Por último, apresentar a possibilidade de explorar contextos que envolvam religiosidade, relacionando a fé e a vida, a vida e o cotidiano com a fé. Neste sentido, as experiências religiosas "são uma base para os jovens dialogarem entre si e com a sociedade", indo ao encontro do que afirma o Referencial Curricular do Ensino Religioso: "o saber de si, o saber dos outros, com os outros".

Ribeiro (2009, p. 242) afirma que a proposta de educar os jovens, levando em conta uma "religiosidade 'naturalmente' humana pode promover uma aproximação entre a diversidade religiosa e algumas conquistas da modernidade, como a ética de um universal humano, transreligioso e transfilosófico".

Faustino Teixeira (2006, p. 35) traz o diálogo inter-religioso como possibilidade para uma educação para a alteridade e para a tolerância e afirma que esta deve começar na infância. Sensibilizar os adultos é, muitas vezes, uma tarefa difícil. Por isso, tanto mais se faz necessário uma educação que respeite as diferenças, pois as "religiões não são apenas genuinamente diferentes, mas também autenticamente preciosas". 
De acordo com Teixeira (2006, p. 33-37), os requisitos para o diálogo inter-religioso são:

- a humildade: "experimenta-se a consciência dos limites e a percepção da presença de um mistério que a todos ultrapassa";

- a convicção religiosa: o diálogo necessita partir de um fundamento, de algo que o sustente;

- a abertura à verdade: "que os interlocutores estejam dispostos, não somente a aprender e receber os valores positivos presentes nas tradições religiosas dos outros, mas igualmente disponíveis e abertos à verdade que os envolve e ultrapassa".

O Ensino Religioso na escola pode ser o espaço para educar para a tolerância, por meio de um diálogo em que haja respeito e sensibilidade para conviver com as diferentes tradições religiosas presentes em sala de aula.

\section{Considerações finais}

Entender e aceitar a diversidade como riqueza e encará-la com alegria é um grande desafio, tanto para as escolas e o Ensino Religioso, como para as comunidades religiosas e para a própria sociedade brasileira. Aqui se situam também as possibilidades para dialogar e aprofundar a pesquisa. Como a escola lida com o desafio de educar para a tolerância e o respeito, levando em conta a diversidade de crenças e de religiões presentes na sociedade? Como os professores do Ensino Religioso dão conta da tarefa de educar para a tolerância e para o respeito pelo outro, a partir de uma realidade de diversidade religiosa, como a brasileira? Essas são questões que merecem pesquisa e reflexão mais aprofundada.

A proposta de diálogo, levando em conta a diversidade, o diferente, o outro e sua maneira de ser e de crer é visto como possibilidade de descobrir e de experimentar o novo e de propiciar um enriquecimento mútuo: "A diversidade religiosa deve ser reconhecida, não como expressão da limitação humana ou fruto de uma realidade conjuntural passageira, mas 
como traço de riqueza e valor. [...] A diferença deve suscitar não o temor, mas a alegria [...]" (TEIXEIRA, 2006, p. 37).

Os contextos brasileiros e a realidade plurirreligiosa podem ser diversificados, mas as grandes questões que se apresentam são quase as mesmas, o que abre a possibilidade de aprendermos uns dos outros e em conjunto para construir um mundo melhor.

\section{Referências}

BOSCARDIN, R. M. Defendendo um ensino religioso interconfessional e ecumênico. Contexto Pastoral, Rio de Janeiro, v. 6, n. 31, p. 9, mar./abr. 1996.

BRASIL. Lei n. 4.024, de 20 de dezembro de 1961. Fixa as diretrizes e bases da educação nacional. Diário Oficial [da] República Federativa do Brasil, Poder Legislativo, Brasília, DF, 27 dez. 1961. p. 11429. Disponível em: <http://www. planalto.gov.br/ccivil_03/Leis/L4024.htm>. Acesso em: 23 nov. 2011.

BRASIL. Lei n. 9.394/96, de 20 de dezembro de 1996. Estabelece as diretrizes e bases da educação nacional. Diário Oficial [da] República Federativa do Brasil, Poder Legislativo, Brasília, DF, 23 dez. 1996a. p. 27833. Disponível em: <http://www6.senado.gov.br/legislacao/ListaTextoIntegral.action?id=75723 > Acesso em: 23 nov. 2011.

BRASIL. Lei n. 9.475, de 22 de julho de 1997. Dá nova redação ao art. 33 da Lei n. 9.394, de 20 de dezembro de 1996, que estabelece as diretrizes e bases da educação nacional. Diário Oficial [da] República Federativa do Brasil, Poder Legislativo, Brasília, DF, 22 jul. 1997. Disponível em: <http://www.planalto.gov. br/ccivil_03/leis/L9475.htm>. Acesso em: 23 nov. 2011.

BRASIL. Lei n. 5.692, de 11 de agosto de 1971. Fixa diretrizes e bases para o ensino de primeiro e segundo graus, e da outras providências. Diário Oficial [da] República Federativa do Brasil, Poder Legislativo, Brasília, DF, 12 ago. 1971. p. 6377. Disponível em: <http://www6.senado.gov.br/legislacao/ ListaTextoIntegral.action?id=75576>. Acesso em: 23 nov. 2011.

Rev. Pistis Prax., Teol. Pastor., Curitiba, v. 4, n. 1, p. 261-276, jan./jun. 2012 
CARON, L. Educação religiosa escolar: ecumenismo em Santa Catarina. Contexto Pastoral, Rio de Janeiro, v. 6, n. 31, p. 8, mar./abr. 1996.

CONFERÊNCIA NACIONAL DOS BISPOS DO BRASIL - CNBB. Regional Sul III. Texto referencial para o Ensino Religioso Escolar. Petrópolis: Vozes, 1996.

CRUZ, T. M. L. Um ensino compatível com a escola. Contexto Pastoral, Rio de Janeiro, v. 6, n. 31, p. 6, mar./abr. 1996.

FOLLMANN, J. I. O mundo das religiões e religiosidades: alguns números e apontamentos para uma reflexão sobre novos desafios. In: SCARLATELLI, C. C. da S.; STRECK, D. R.; FOLLMANN, J. I. (Org.). Religião, cultura e educação. São Leopoldo: UNISINOS, 2006. p. 11-28.

GRUPO DE TRABALHO DO ENSINO RELIGIOSO INTERCONFESSIONAL GTERI. Proposta para um Ensino Religioso Interconfessional. Texto não publicado.

MEDEIROS, I. S. Ensino Religioso: na escola não. Contexto Pastoral, Rio de Janeiro, v. 6, n. 31, p. 7, mar./abr. 1996.

PADRE ROQUE. Ensino Religioso: uma grande mudança - Propostas para mudar a LDB. Substitutivo que apresenta o ensino religioso como parte integrante da nova lei. Brasília: Centro de Documentação e Informações/Coordenação de Publicações, 1998.

RIBEIRO, J. C. Religiosidade jovem: pesquisa entre universitários. São Paulo: Olho d'Água; Loyola, 2009.

ROMANELLI, O. de O. História da educação no Brasil. (1930-1973). 13. ed. Petrópolis: Vozes, 1991.

SCHULTZ, A. Diversidade religiosa e os desafios para o Ensino Religioso. In: BRANDENBURG, L. et al. (Org.). Fenômeno religioso e metodologias. São Leopoldo: Sinodal, 2009. p. 20-30.

SOBEL, H. Religião e escola pública. Contexto Pastoral, Rio de Janeiro, v. 6, n. 31, p. 6, mar./abr. 1996. 
TEIXEIRA, F. Diálogo inter-religioso e educação para a alteridade. In: SCARLATELLI, C. C. da S.; STRECK, D. R.; FOLLMANN, J. I. (Org.). Religião, cultura e educação. São Leopoldo: UNISINOS, 2006. p. 29-40.

VIESSER, L. C.; VIDOTTI, M. S. S.; BOSCARDIN, R. M. Referencial Curricular para a Proposta Pedagógica da escola. Curitiba: FONAPER, 2000. (Caderno Temático n. 1).

VIESSER, L. C.; WAGNER, R.; BOHNE, V. V. E. Parâmetros curriculares nacionais: Ensino Religioso. 2. ed. São Paulo: AM Edições, 1997. (Fórum Nacional Permanente do Ensino Religioso).

Recebido: 22/05/2011

Received: 05/22/2011

Aprovado: 23/07/2011

Approved: 07/23/2011 